\title{
POLICY ANALYSIS WITH A DISAGGREGATED ECONOMIC-DEMOGRAPHIC MODEL*
}

\author{
Robin BARLOW \\ University of Michigan, Ann Arbor, Mich. U.S.A. \\ Gordon W. DAVIES \\ University of Western Ontario, London, Ont., Canada
}

First version received December 1972, revised version received July 1973

\section{Introduction}

The purpose of this paper is to show that useful information about a wide variety of proposed government policies can be obtained through simulation experiments with a detailed macroeconomic model. In particular, the simulation technique can provide information about the effects of a policy on the long-run growth of per capita income. Since accelerating the growth of per capita income is usually an important national goal, especially in underdeveloped countries, this kind of information should be of special interest to the authorities who must decide which policies to adopt and which to reject.

The advantage of using a macroeconomic model in evaluating an individual policy is that the mode! permits one to recognize various indirect effects or repercussions which are generally ignored in standard techniques of evaluation. Consider, for example, a policy of increasing enrolment in secondary schools. A standard procedure here would involve comparing the increase in the future earnings of the additional students with the cost of the policy. ${ }^{1}$ But this would ignore various other ways in which the policy may affect economic well-being. In particular, an expansion of education among teenage girls is likely to cause a reduction in fertility rates, with generally positive effects on the growth of per capita income. Furthermore, the wage-rates which govern the size of the direct return to secondary schooling are not really exogenous, as assumed in conventional benefit-cost analysis, but may be affected by the policy itself. If the policy

*The authors wish to acknowledge gratefully the helpful suggestions received from Harvey E. Brazer and William B. Neenan on an earlier draft of this paper, but accept responsibility for errors remaining. Financial support for the project was generously provided by the Pan American Health Organization and the University of Michigan's Center for Research on Economic Development.

${ }^{1}$ For an example of such an approach, see Bowles (1967). 
causes a significant rise in output and saving, and hence in the amount of capital per worker, wage-rates can be expected to rise in the future. Only through the use of a model which specifies the various relationships between educational attainment, fertility, output, the capital stock, and wage rates can the indirect effects be properly recognized.

The technique of using a macroeconomic model to simulate the effects of selected government policies on the future course of target variables is well established. ${ }^{2}$ In the present study, we attempt to apply the technique to a broader range of policies than has hitherto been covered. In particular, we concern ourselves with projects in the fields of education and health, involving investment in human capital. This concern has meant refining the labor sector in the inacroeconomic model to an unusual degree. The size of the labor force, moreover, is not given exogenously, as is usually the case in macroeconomic models, but instead is determined by a large number of demographic and economic variables. All of these are in turn endogenous, except for those which are directly controlled by government, such as military service rates. The sizes of the population cohorts, for example, depend on past birth and death rates, which are themselves linked to various economic and demographic variables. The greater the interdependence achieved within the model, the greater the degree of realism. The present study may thereforc point to ways of building better analogs of actual economic systems, apart from its intended contributions in the sphere of policy analysis.

A summary of the model is presented in the following section. To illustrate the model's usefulness and versatility in the evaluation of policies, its parameters are then assigned values which are typical of low-income economies, and simulations are performed to show the effects of a wide variety of policies on the growth of per capita income. In other words, the model is employed to show what consequences the policies would have in a hypothetical but representative underdeveloped economy. The policies selected here are as follows:

(1) malaria eradication;

(2) birth control;

(3) malaria eradication in combination with birth control;

(4) disarmament.

After the summary description of the model, we turn to a discussion of the simulated effects of these policies. In the final section, we report the findings of some sensitivity analysis, which tell us to what extent the results are sensitive to the particular values assumed for the parameters of the model.

We conclude from these experiments that authorities concerned with policy analysis in an underdeveloped country would do well to consider building and

\footnotetext{
${ }^{2}$ See, for example, Coale and Hoover (1958), Holland and Gillespie (1963), Fromm and Taubman (1968), Enke and Zind (1969), Denton and Spencer (1971), Davies (1972), and Enke et al. (n.d.).
} 
maintaining a model of the kind illustrated here. The set-up costs may appear considerable, but it should be recognized that the economies of scale in an enterprise of this sort are substantial. A model once built can be used for evaluating an indefinite number of policies. The costs of maintaining the model arise mainly from altering the values of the parameters as new information comes to light. These costs are not negligible, but they will usually be small in comparison with the cost of initial construction.

\section{Summary of the model}

In this section we provide a brief description of the model employed in evaluating our selected policies. Since we are particularly interested in policies involving investment in human capital, the model, as noted above, is most detailed in its specification of the quantity and quality of labor inputs. A complete description of the model, using symbolic notation, is provided in appendix A below.

We are concerned primarily with measuring the effects of the selected policies on income per equivalent consumer. Income or output is principally a function of the quantity and quality of both labor and capital. The model can therefore be divided into six segments, corresponding to the variables just mentioned: the population of equivalent consumers, income, the quantity of labor, the quality of labor, the quantity of capital, and the quality of capital. Each of these segments will be described in turn.

\subsection{Determination of the population of equivalent consumers}

(i) In counting the population of equivalent consumers, each individual is assigned a weight equal to the ratio between his 'consumption needs' and the needs of some standard group, such as adult males, The target variable in this study is defined as income per equivalent consumer rather than income per capita, on the grounds that the former concept is a more refined measure of economic well-being.

(ii) The population cohorts from which the population of equivalent consumers is derived are disaggregated by age (single years of age from zero through 64 , and then ' 65 or over'), sex, and education. ${ }^{3}$ Cohorts aged under eleven are differentiated only by age and sex. Cohorts aged between eleven and seventeen

${ }^{3}$ The population cohorts are defined by single years of age (for example, males aged 7 , aged 8 , aged 9 , and so forth) because the single year is the basic period of analysis used in the study. To yield annual data on output, the model calls for annual data on the size of various population subgroups, and these latter data are most readily obtained if the total population is already defined by single years of age. The procedure greatly increases the size of the tota! model (which ended up containing 1,690 equations), and does add a certain tedium to the task of making initial preparations for computer work, but on balance is preferable to the alternatives. 
are differentiated by age and sex, and additionally by whether or not their members had completed primary school. Cohorts aged over seventeen are differentiated by age and sex and by whether their members had completed secondary school, primary school only, or neither. Hence in any one year the sizes of 338 cohorts have to be determined. The reason for differentiating the cohorts by educational attainment is that this variable is closely related to many others which play a part in the model, like disease rates, unemployment rates, and fertility rates.

(iii) The population aged zero is given by the number of births occurring within the previous year, adjusted appropriately for infant mortality. The number of births is obtained by applying age-education-specific fertility rates to the relevant female population cohorts. These fertility rates are dependent on lagged infant mortality (because some births may represent attempts to replace children lost through death), income per equivalent consumer (representing the influence of current economic conditions), a trend term to reflect improvements in medical technology (leading to fewer miscarriages and stillbirths), and an exogenous term reflecting the influence of birth control programs.

(iv) The population at each age above zero is given by the population one year younger in the previous year, adjusted for mortality. Death rates are defined separately for sex-age-education groups (ten-year age-brackets being used throughout most of the age range), and are functions of income per equivalent consumer, a trend term which reflects improvements in medical technology, and an exogenous term reflecting the influence of public health measures. In addition, death rates among children under eleven are affected by the average level of educational attainment among women of child-bearing age. This relationship recognizes the effect of education on standards of child care.

\subsection{Determination of income}

The level of income in each year of the simulation period is given by a fourinput production function which assumes a constant elasticity of substitution between each pair of the four inputs or factors. ${ }^{4}$ These factors include capital and three varieties of labor distinguished by educational attainment. Each of the four factors in the function is characterized by a quality index. The function also includes terms to reflect economies of scale and secular improvements in resource allocation.

\subsection{Determination of labor quantity}

(i) The quantity of labor is defined as the aggregate annual number of hours

\footnotetext{
${ }^{4}$ The assumption of a single elasticity of substitution for the four pairs of factors is clearly an oversimplification, but allowing for different elasticities would have increased very substantially the complexity of the production function. For a discussion of the properties of the constant-elasticity-of-substitution function, see Arrow et al. (1961).
} 
of work. This total is obtained for each of the three varieties of labor by adding the hours worked by the members of the appropriate sex-age-education population cohorts. The hours worked by each cohort are obtained by multiplying the number of workers in the cohort by the average number of hours worked.

(ii) The average number of hours worked is defined separately for each sexage-education group and also varies with income per equivalent consumer (serving as a reasonable proxy for the average wage-rate), and morbidity (defined here as sickness causing absence from work). ${ }^{5}$

(iii) Morbidity rates, like death rates, are governed by sex, age, education, income per equivalent consumer, a trend term, and a term reflecting the effects of public health projects.

(iv) The number of workers in each cohort is obtained by subtracting four categories of nonworkers from the population of the cohort: students, military personnel, other nonparticipants, and the unemployed. Rates of school attendance, military service, 'other nonparticipation', and unemployment are defined for each sex-age-education group.

(v) School attendance rates vary not only with sex, age, and education, but also with income per equivalent consumer (again a proxy for the average wagerate, and hence reflecting both the future returns and the present opportunity cost of additional s'hooling) and with lagged per pupil expenditures at the grade level in question (on the grounds that attendance rates are likely to be positively related to the expected quality of the schooling). The attendance rates are also dependent on an exogenous term reflecting the effects of government policy. Military service rates are exogenous.

(vi) The rates of 'other nonparticipation' are related to age, sex, and education, and to income per equivalent consumer (a proxy for the average wage-rate). Unemployment rates by sex, age, and education groups are related to the aggregate capital-labor ratio. Implicit in this formulation is a 'supply-side' theory of unemployment, often espoused in the literature on economic development, according to which the number of persons employed will increase if the amount of capital available for them to work with is increased. A situation of this kind is compatible with profit-maximization if wages are set by institutional factors at a fixed level, related perhaps to subsistence requirements. which is in excess of the marginal revenue product of labor. ${ }^{6}$

\footnotetext{
${ }^{5}$ The use of income per equivalent consumer as a proxy for the average wage-rate is a convenience, since the income variable already exists in the model, where it is used for other purposes, while the creation of wage variables would involve specifying additional equations. The model could of course yield wage values without too much difficulty if wages were assumed to be systematically related to marginal or average product, hecause marginal or average product, disaggregated by educational attainment categories if necessary, could be calculated directly from the production function.

${ }^{6}$ For a discussion of this situation and its relevance for planning models, see Chakravarty (1969). At first glance it may seem that the existence of unemployment is incompatible with the CES production function specified above. However, this function renders unemployment impossible only if the assumptions are made that all labor markets are perfectly competitive and that wages are flexible downwards. These assumptions do not have to be made. The labor
} 


\subsection{Determination of labor quality}

(i) Each of the three labor-input variables appearing in the production function is multiplied by an index of labor quality. Each of these global indexes is the weighted average of the quality indexes characterising the appropriate population cohorts. The weight applied to each of these individual cohort indexes is the number of hours worked by members of the cohort in question.

(ii) The quality index for each cohort is based on three variables: the average stock of educational capital accumulated by the non-student members of the cohort, the average amount of on-the-job training accumulated by the cohort members, and their debility (defined as sickness causing a loss in effectiveness on the job).

(iii) The stock of educational capital possessed by each cohort is measured by the cumulated sum of the educational expenditures made on behalf of the cohort members in previous years. Educational expenditures per pupil at each grade (primary, secondary, and higher) are determined jointly by school attendance rates. the size of the total educational budget, and the ratios between per pupil expenditures at the three grades. All of these three determinants are in some degree subject to government control.

(iv) The amount of on-the-job training accumulated by the members of a cohort depends on the number of hours which they have worked in past years. The assumption is made that the proportion of hours worked which are devoted to on-the-job training varies positively with the educational attainment of the workers receiving the training. The fraction of work-time spent receiving on-thejob training is assumed to decline with age.

(v) Debility rates are governed by the same set of factors as morbidity rates and death rates.

\subsection{Determination of capital quantity}

(i) The size of the capital stock at any point in time equals the size one year previously, adjusted for the depreciation and investment occurring in the interim. Allowance is made for varying gestation periods of investment.

(ii) Gross investment is determined by the amount of depreciation, private saving, and public saving. That is, an 'availability-of-funds' theory of investment behavior is assumed, rather than one based upon the demand situation or expected profitability.

(iii) Private saving is related to private disposable income, the size of the population at dependent ages (under 15 and over 64), and the inflow of foreign private capital. ${ }^{7}$ Private disposable income is defincd nct of private expenditures

terms in the production function, it will be noted, refer to employed labor and not to the potential labor force.

7 The form of this function is based on one tested empirically by Leff (1969). The treatment of foreign capital inflows in our model is somewhat unorthodox. These inflows are treated as a type of income part of which may be saved rather than as (definitionally) the difference between 
on medical care, in order to recognize that reduced morbidity is likely to lessen the demand for medical care and will thus release some funds to private saving.

(iv) Public saving is defined as the excess of tax receipts and foreign economic and military aid over current government expenditures.

(v) Tax receipts are governed by income, imports, and exports. ${ }^{8}$ Imports are determined by the quantity of foreign exchange available, that is, by export proceeds and foreign capital inflows. Exports are assumed to grow exogenously at a constant rate, an assumption which reflects the 'enclave' nature of export sectors in many underdeveloped countries.

(vi) Current government expenditures are divided into five categories: expenditures for education, public health, the armed forces, transfers, and other services. The amount of spending in each of these categories is determined by the revenues available, by the size of the client population (except in the case of military spending), and by whether a particular policy under evaluation (such as malaria control in the public health category) is assumed to be instituted.

\subsection{Determination of capital quality}

(i) The index of the quality of the capital stock changes in each year as a result of differences between the quality of the stock at the beginning of the year, the quality of that part of the stock which disappears during the year through depreciation, and the quality of the new investment added to the stock during the year.

(ii) The quality of each year's investment is determined by the fraction of the total investment which consists of imported capital goods (presumed to have a relatively high quality or productivity), the size of the domestic capital goods industry relative to the rest of the economy (on the grounds that a given outlay will buy more goods if the economies of scale permitted by a large-sized sector are operative), and on trend terms representing embodied technological progress. $^{9}$

investment and domestic saving. Our procedure has the advantage of allowing us to recognize that different types of receipts may be subject to different saving propensities.

${ }^{8}$ Empirical support for the form of this function is provided by Lotz and Morss (1970).

${ }^{4} Q$ uality indexes were adopted for different components of the capital stock in an attempt to reflect the economic structure implied by the 'two-gap' models which are widely used in analyzing policy problems of underdeveloped countries. For an example of the two-gap approach, see Chenery and Eckstein (1970). According to this approach, economic growth is constrained by either a saving gap or a trade gap. If the foreign exchange constraint is operative, growth cannot be accelerated by any further domestic saving, that is to say, by any expansion in the output of domestically produced capital goods. These goods cannot be substitutad for imported capital goods, which can therefore be viewed as being more productive or of higher quality. A problem with using the quality indexes, as two referees of this paper have pointed out, is that the capital variable, being expressed in monetary terms, already incorporates the quality element. The prices of capital goods presumably reflect their quality. A better approach, if the two-gap model is thought to be valid, might be to treat domestically produced capital and imported capital as separate inputs in the output function, with appropriate degrees of substitutability between each other and the labor inputs. 
(iii) Imported capital goods are a constant fraction of total imports.

The method of constructing the model, and the way in which it works, can perhaps be further clarified by a diagram showing how the major variables are related to each other. Fig. 1 presents a simplified version of the model in diagrammatic form. At the top is the target variable of major interest, income per equivalent consumer. The level of this variable is determined by the levels of population and income, which appear directly beneath it. Population is determined by fertility and mortality, and income in this simplified version, is determined by three variables - labor quality, hours worked (or labor quantity), and

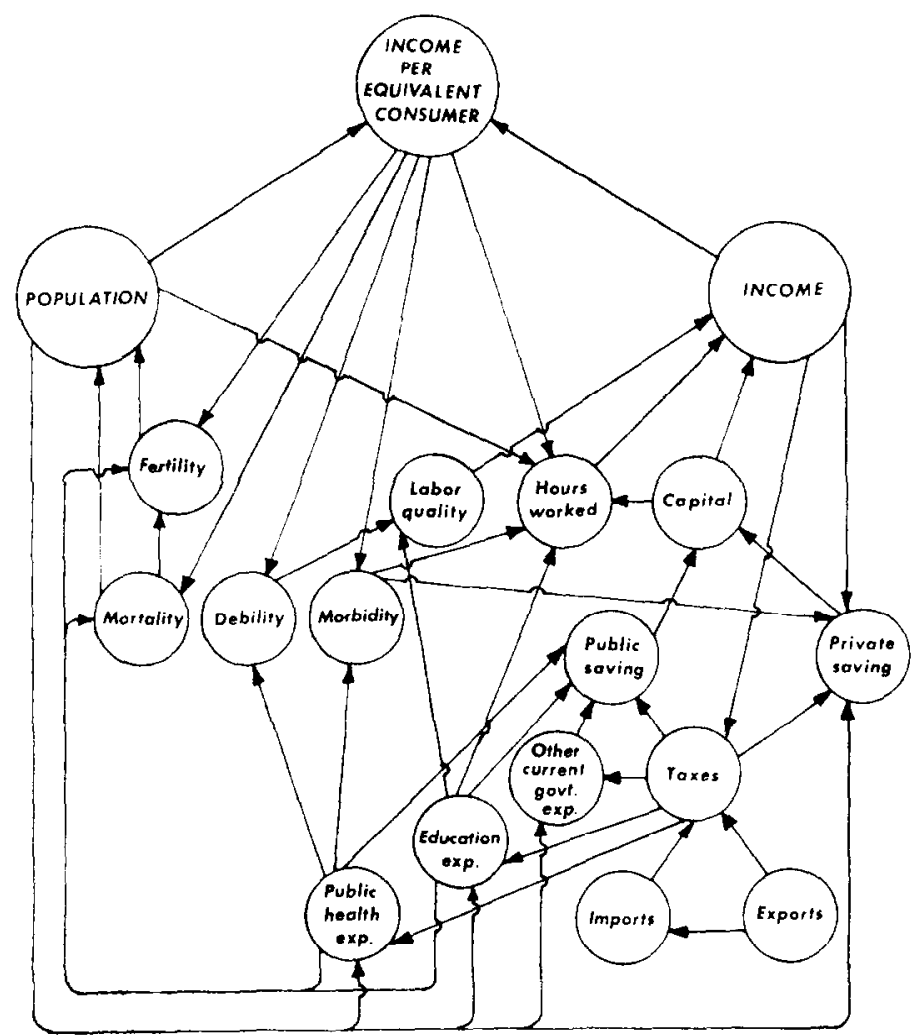

Fig. 1. Relations between variables in simplified model.

capital. These three are in turn affected directly or indirectly by public sector variables subject to policy action - taxes and various categories of government spending.

The arrows between the variables, indicating the direction of causation, provide a clear impression of the high degree of interdependence in the system. Only one of the eighteen variables appearing in this simplified version - exports is exogenous, the source of arrows but the destination of none. The inter- 
dependence can be illustrated by the role of the education spending variable, which is directly linked to seven other variables in the schema. Education expenditures are determined partly by (1) the volume of tax revenues available and partly by (2) the size of the client population, in this case children of school age. An increase in these expenditures will, after a lag, produce an improvement in (3) labor quality, but there will be negative effects on (4) hours worked (because students are assumed to be more likely to stay in school and out of the labor force if the quality of schooling is raised) and on (5) public saving. The higher levels of educational attainment which follow from the increased spending lead to higher standards of child care and hence to a decrease in (6) mortality and by such mechanisms as the postponement of marriage also reduce $(7$, fertility.

\section{Evaluation of selected projects}

The model described above was used to measure the long-term effects of several different government policies on income per equivalent consumer. Values for the parameters were assigned which were thought to be typical for underdeveloped countries. A variety of empirical studies and personal impressions were used in making these assignments. (The parameter values and statistical sources are listed in appendix $C$ below.) In this way a hypothetical economy was created. At the start of the period of analysis (year 1), this economy had a population of 8.26 million. The population of equivalent consumers was 6.92 million, children and women being counted as fractional consumers. Income was $\$ 892$ million, and income per equivalent consumer was therefore \$129. The model was then employed to simulate the course of income per equivalent consumer over the next thirty years on the assumption that none of the selected policies had been instituted. At the end of the period of analysis (year 31) the population had grown to 14.40 million, the population of equivalent consumers to 11.82 million, income to $\$ 2553$ million, and income per equivalent consumer to $\$ 216$. The implied average annual rates of increase were 1.9 per cent for the population, 1.8 per cent for the population of equivalent consumers, 3.6 per cent for income, and 1.7 per cent for income per equivalent consumer. ${ }^{10}$

Each of the selected policies was then instituted in turn (each one starting in year 2), and the simulations were repeated. Comparisons could then be made between the path of income per equivalent consumer with each policy and the path without it. We now discuss the results of these simulations.

\subsection{Malaria eradication}

The adoption of the malaria eradication policy involved immediate reductions

\footnotetext{
${ }^{10}$ These modest rates of increase, occurring over a prolonged period of simulation, suggest that the model was reasonably stable. All other simulations pointed to the same conclusion.
} 
in the rates of mortality, morbidity, and debility and also a rise in fertility rates. " There was also a gradual improvement in the allocation of resources as labor and capital were moved into fertile regions previously shunned through fear of the disease. The direct costs of the policy (for example, purchases of DDT and wages of spraymen) added a small amount to the public health category of the budget.

The effect of the policy on the growth of income per equivalent consumer is

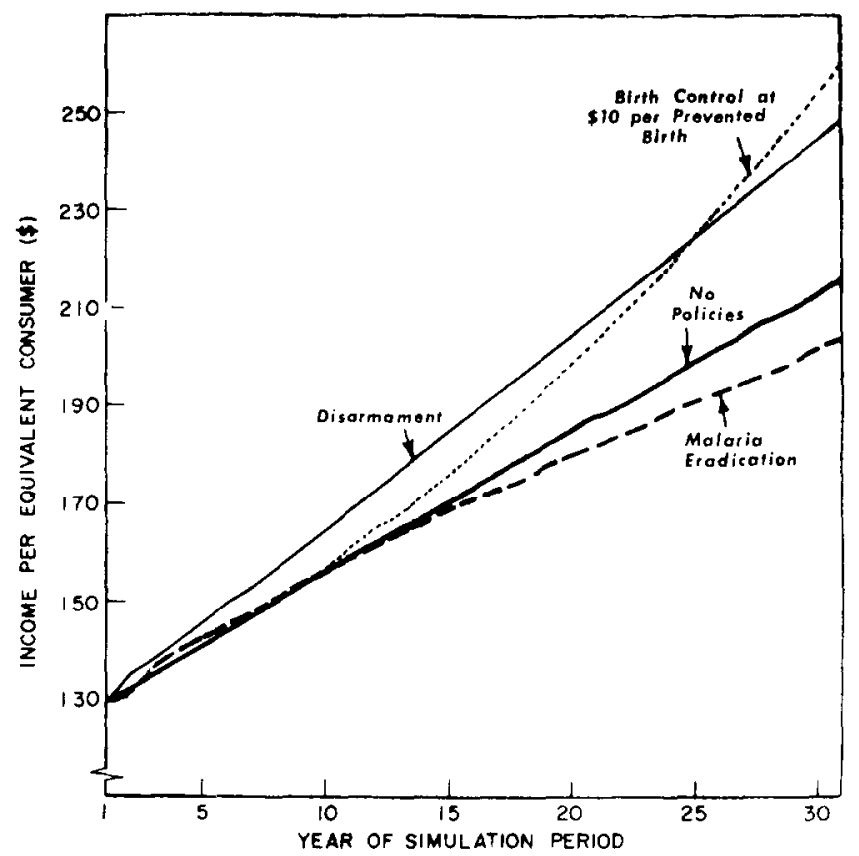

Fig. 2. The effects of selected policies on the growth of income per equivalent consumer

shown in fig. 2. The effect was positive for the eight years following the adoption of the policy, and negative thereafter. By year 31 , income with malaria eradication was 15 per cent higher than otherwise. But the population of equivalent consumers was 22 per cent higher, and the level of income per equivalent consumer was therefore 6 per cent lower than the level reached without the policy. This general result duplicates nne obtained in an earlier study by one of the present authors [Barlow (1969)].

The positive short-run effects of malaria eradication on the growth of income per equivalent consumer were due to its immediate effect on the quantity and

\footnotetext{
"Malaria tends to reduce fertility rates by causing miscarriages. The estimates of the mortality and fertility effects of the hypothetical project are derived from Newman (1965). The estimates of the morbidity and debility effects are derived from an earlier study by one of the present authors [Barlow (1969)].
} 
quality of labor. Fig. 3 shows the quick expansion in the total quantity of labor, which is measured as the sum of the three types of labor input appearing in the production function (secondary school graduates, primary school graduates, and nongraduates). This expansion was more the result of reductions in morbidity than of reductions in mortality. Most of the deaths prevented by malaria eradication were among infants, who did not enter the labor force in appreciable numbers until much later. The quick improvement in the quality of labor occurred because of reduced debility. By year 3, the index of labor quality among nongraduates had already reached with the policy a level 4 per cent higher than it would have been otherwise. (Among primary and secondary graduates, the increases in the quality indexes were somewhat smaller, a fact which reflects

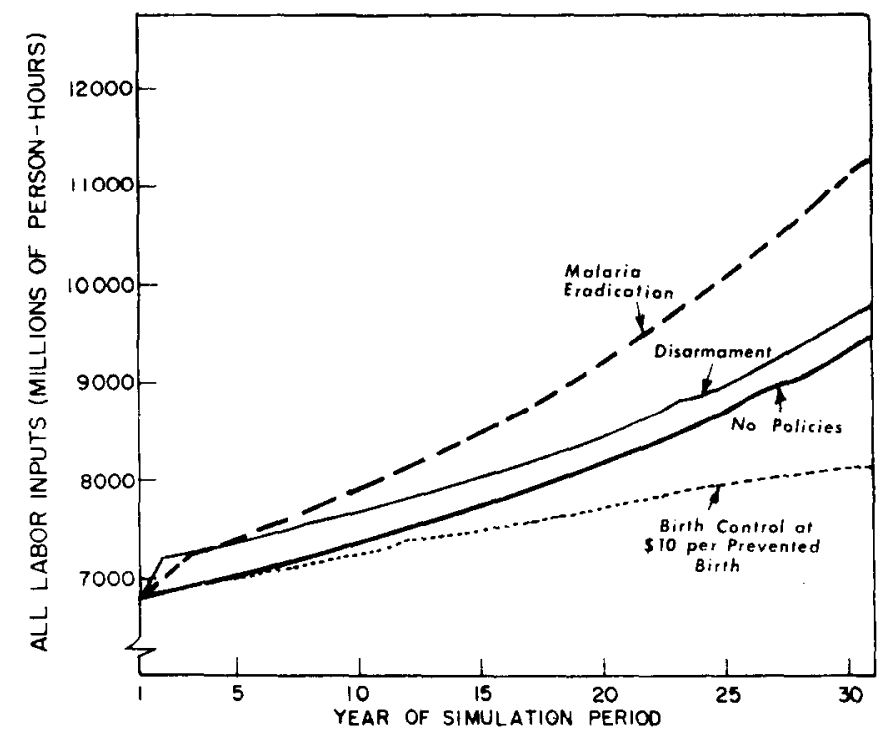

Fig. 3. The effects of selected policies on the growth of labor inputs.

the lower incidence of malaria among persons of better cducation and higher income.) These positive consequences were reinforced by the geographical reallocation of resources already mentioned and by the additional household saving occurring as a result of reduced morbidity. With less morbidity, there was less need to spend money on medical care.

Eventually, the policy had a negative effect on income per equivalent consumer. The growth in income attributable to the policy was after a few years surpassed by the growth in the population. The reason for the relatively slow growth of income was that the expansion of the labor inputs was at least partly offset by a contraction of capital inputs. The increase in population had the effect of stimulating current expenditures in both the public sector and the 
private, with the result that investment suffered a decline. The negative effects of malaria eradication on investment are shown in fig. $4 .^{12}$

\subsection{Birth control}

In year 1 , there was a crude birth rate of $4 \mathrm{I}$ per thousand in the prototype economy. The birth control policy consisted of preventing a sufficient number of births to bring about a reduction of one point in the crude birth rate each year

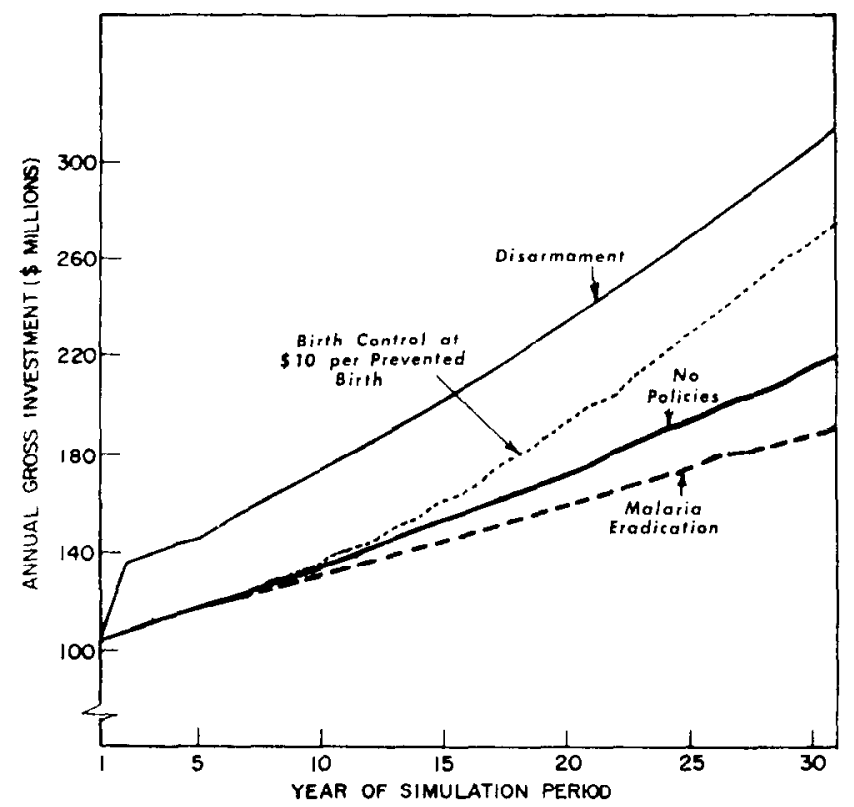

Fig. 4. The effects of selected policies on the growth of investment.

for fifteen years. The costs of the policy, which were an addition to the public health category of the government's current expenditures, were initially assumed to be $\$ 10$ per prevented birth. In an attempt to gain some indication of how expensive the policy could be before becoming unprofitable, an alternative cost assumption of $\$ 50$ per prevented birth was made.

The effect of birth control on income per equivalent consumer under the first of these cost assumptions is shown in fig. 2. The policy brought about a large

\footnotetext{
${ }^{12}$ The fact that malaria eradication may reduce income per equivalent consumer in the long run is not, of course, by itself a reason for rejecting such a program. Other social objectives besides economic growth will normally be important, and positive contributions made by eradication towards these other objectives - such as the reduction of mortality - may be viewed as outweighing its negative effects on growth. It can be noted that the model used here can provide information relevant for many social objectives besides growth, for example, those in the areas of mortality, morbidity, debility, unemployment, and income inequality.
} 
increase in income per equivalent consumer. In year 31 , income per equivalent consumer was 21 per cent higher with birth control than it would have been without it. The assumption of the higher cost figure made virtually no difference to the size of the payoff to birth control. With the prevention of each birth costing $\$ 10$, income per equivalent consumer in year 31 was $\$ 260$; with each prevention costing $\$ 50$, the figure was $\$ 257$. Further experiments of this kind could indicate the 'break-even' cost of a birth control policy, that is, the unit cost at which the policy's contribution to future income per equivalent consumer would be reduced to zero. Clearly the break-even cost would be very high, perhaps as much as $\$ 500$ per prevented birth.

The mechanism by which the birth control policy produced it: results is indicated in figs. 3 and 4 . The policy made a negative contribution to the quantity of labor inputs, but any negative effect which this may have had on income was offset by the policy's positive contributions to investment. With families smaller, saving propensities were increased in both the private and public sectors. Moreover, the negative impact on the quantity of labor inputs did not become significant until many years had elapsed. As for the effect of the birth control policy on labor quality, this too was positive. Higher incomes per equivalent consumer meant less debility and better education. By year 31, the index of labor quality among primary graduates, for example, had reached 3.14 under conditions of birth control; without the policy the figure was only 2.91 .

\subsection{Malaria eradication and birth control}

The next policy consisted of a combination of the two previous ones. ${ }^{13}$ It was felt that malaria eradication and birth control might interact with each other in such a way that the effect of the combined policy on the growth of income per equivalent consumer would be significantly different from the sum of the effects of the two policies operating in isolation. As it turned out, very little interaction was discerned. Malaria eradication by itself subtracted $\$ 12$ from income per equivalent consumer in year 31 , while birth control (at a cost of $\$ 10$ per prevented birth) added $\$ 44$. On the assumption of no interaction, one might conclude that a combination of the two policies would add $\$ 32$ ( $\$ 44$ minus $\$ 12$ ) to income per equivalent consumer. In fact the combination added an amount only $\$ 5$ less than that.

\subsection{Disarmament}

The disarmament policy involved reducing the rates of military service

\footnotetext{
${ }^{13}$ The birth control policy involved reducing fertility rates to achieve an annual reduction of one point in the crude birth rate. Because of the stimulative effect of malaria eradication on fertility, the two policies in combination resulted in a fall in the birth rate which was less than one point per period
} 
applying to the various sex age education cohorts, reducing also the share of the armed forces in the government budget, and accepting a reduction in the inflow of foreign military aid. The result of all this, as shown in fig. 2, was a significant increase in income per equivalent consumer. By year 31 , disarmament had raised income per equivalent consumer by 15 per cent.

Disarmament produced these effects by augmenting both labor inputs and capital inputs, as indicated in figs. 3 and 4 . The reduction in military service rates led to an immcdiate increase in labor inputs. The reduction in military expenditures was only partly offset by the cut in foreign aid, and disarmament therefore had the effect of raising public saving and hence investment.

A number of other policies in the area of education and taxation were examined, including increasing the education budget, raising all school attendance rates, diversion of education expenditures between grades, and increasing tax revenues. These policies were found to have very little effect on the growth of income per equivalent consumer. The growth curve for cach of these policies was not perceptibly different from the 'No Policies' curve shown in fig. 2, and the results of these simulations have therefore not been charted here. In each case the policy generated some negative effects on the growth of income per equivalent consumer which roughly offset its positive contributions.

\section{Sensitivity analysis}

In a large macroeconomic model like the one discussed in this paper, there will naturally be many irnportant parameters which are difficult to estimate due to a lack of data. If the model is to be used for policy analysis, it is therefore desirable to identify each of these parameters, assign alternative values to it (for example, a 'high' value, a 'medium', and a 'low'), perform a separate simulation for each assumed value, and in this way see whether the judgment about the policy is sensitive to the particular value assumed for the parameter in question.

In concluding our paper, we present an illustration of this kind of sensitivity analysis. The elasticity of factor substitution was selected as a parameter which was both important and difficult to measure. In the basic simulations reported above, a 'medium' value of 0.9 was assumed for this relationship between the four factors in the production function. ${ }^{14} \mathrm{~A}$ 'low' value of 0.3 and a 'high' value of 1.5 were then assumed in turn, and the simulations were repeated for both the case of no policies and the case of malaria eradication. The results of these experiments are shown in fig. 5 .

\footnotetext{
${ }^{14} \mathrm{~A}$ value of 0.9 for the elasticity of factor substitution means that, as regards any two of the four factors (capital, secondary school graduates, primary school graduates, and nongraduates), a 0.9 per cent change in the ratio of their (quality-weighted) quantities is accompanied by a 1 per cent change in the ratio of their marginal products.
} 
The sensitivity analysis indicates that the basic effects of malaria eradication on the growth of income per equivalent consumer were independent of the degree of factor substitutability. For all assumed degrees of substitutability, eradication made initially a positive contribution to income per equivalent consumer but ultimately a negative contribution. The 'cross-over point' - the year when the contribution of eradication first became negative - did of course

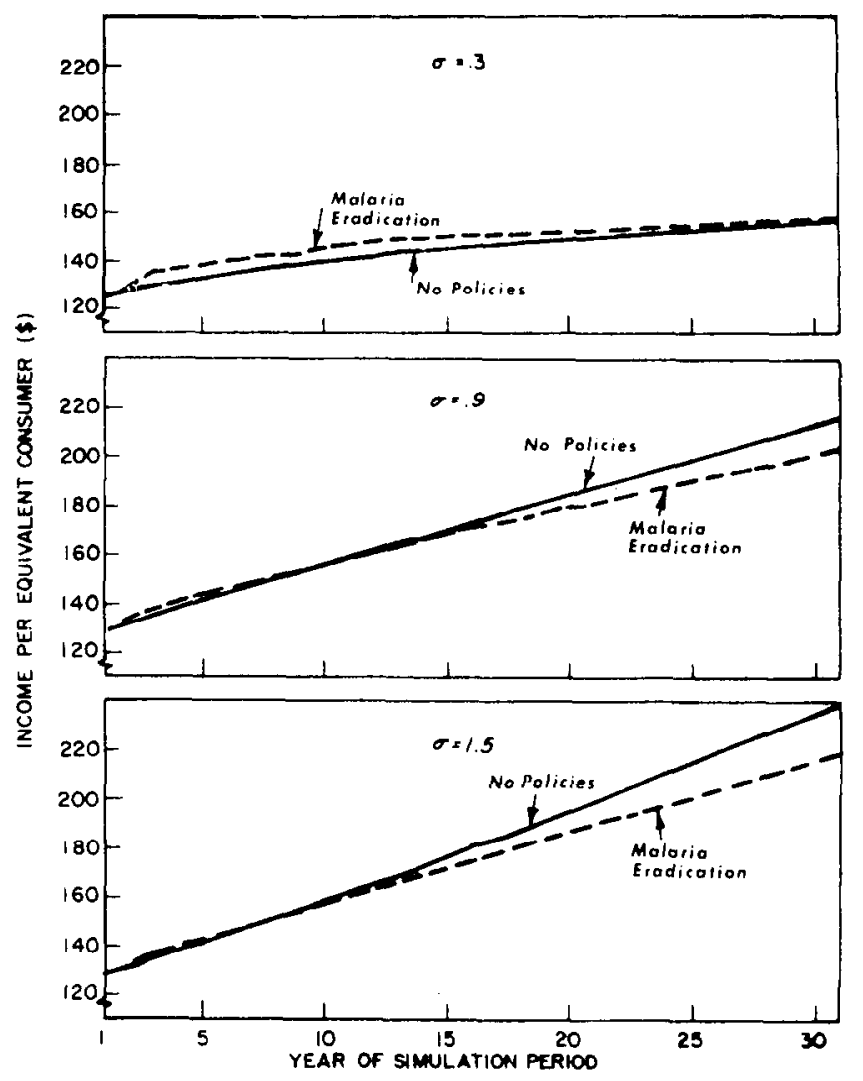

Fig. 5. Sensitivity analysis: The effects of alternative assumptions about the elasticity of factor substitution $(\sigma)$ on the evaluation of malaria eradication.

vary with the assumed degree of substitutability. With elasticity values of 1.5 and 0.9 , this point occurred in years 7 and 11 respectively. With a value of 0.3 , the point did not occur within the thirty-year period of analysis, although fig. 5 clearly suggests that it would have occurred by year 35 or thereabouts.

How should the decisionmaker react to these results? If future net benefits are to be significantly discounted, which means ignoring events occurring after, say, year 30 , then the economic worth of malaria eradication seems to depend critically on the degree of Cactor substitutability. With an elasticity value of 0.3 , 
the verdict on the policy would be favorable; with a value of 0.9 or more, it would be unfavorable. Further research into the matter of substitutability would therefore be indicated.

\section{Appendix $\mathbf{A}^{15}$}

\section{Model equations}

Listed below are the equations of the model discussed in this paper. The sequence of the equations is patterned after the summary of the model appearing in the body of the paper. Endogenous variables are symbolized by upper-case letters, and exogenous terms by lower-case letters.

Determination of the population of equivalent consumers

$$
\begin{aligned}
& P C_{t}=\Sigma_{i} c a_{i, j} P_{i, j, t} \\
& P_{i, \breve{j}, k, t}=b r_{i} B_{t-1}\left(1-D_{i, 0, t-1}\right) \quad[j=0] \\
& P_{i, j, k, t}=A_{i, j-1, k-1, t-1} P_{i, j-1, k-1, t-1}\left(1-D_{i, j, k-1, t-1}\right) \\
& {[j=11 \text { and } k=p \text {; }} \\
& j-18 \text { and } k=s \text { ] } \\
& P_{i, j, k, t}=\left(1-A_{i, j-1, k-1, t-1}\right) P_{i, j-1, k-1, t-1}\left(1-D_{i, j, k-1, t-1}\right) \\
& \text { [ } j=11 \text { and } k=n \text {; } \\
& j=18 \text { and } k=p \text { ] } \\
& P_{i, j, k, t}=P_{i, j-1, k, t-1}\left(1-D_{i, j, k, t-1}\right) \quad \text { [all sex-age-education } \\
& \text { classes not covered } \\
& \text { by eqs. (2) - (4)] } \\
& B_{t}=\Sigma_{j, k} P_{f, j, k, t} F_{j, k, t} \\
& F_{j, k, t}=\left[f a_{j, k} /\left(1-f b_{\bar{j}, k} D_{m, 0, t-2}\right)\right](1+f c)^{t U-1 \iota^{\prime d j}}-f e_{j, k, t} \\
& D_{i, j, k, t}=1 /\left[1+\left(d a_{i, j, k}+d b_{j} P_{f, 11-44, s \& p, t} / P_{f, 11-44, i}\right)\right. \\
& \left.\times\left(1-d c_{i, j, k}\right)^{-t} U_{t-1}^{d d_{i, j, k}}\right]-d e_{i, j, k, t}
\end{aligned}
$$

Determination of income

$$
Y_{t}=y a(1+y b)^{t}\left[y c\left(K_{t} Q K_{t}\right)^{-y s}+\Sigma_{k} y d_{k}\left(L_{k, t} \bar{Q} \bar{L}_{k, t}\right)^{-y s}\right]^{-y e / y s}
$$

\footnotetext{
15 Footnotes a-d at the end of appendix $A$.
} 
Determination of labor quantity

$$
\begin{aligned}
L_{k, t}=\sum_{i, j} & H_{i, j, k, t} W_{i, j, k}, \\
H_{i, j, k, t}= & h a_{i, j, k} U_{t-1}^{h b}\left(1-M R_{i, j, k, t}\right) \\
M R_{i, j, k, t}= & 1 /\left[1+r a_{i, j, k}(1-r b)^{-t} U_{t-1}^{r c}\right)-r d_{i, j, k, t} \\
W_{i, j, k, t}= & P_{i, j, k, l}\left(1-A_{i, j, k, 1}\right)\left(1-m s_{i, j, k, t}\right)\left(1-N P_{i, j, k, t}\right) \\
& \times\left(1-U N_{i, j, k, t}\right) \\
A A_{i, j, k, t}= & a a_{j, k} /\left[1+a b_{i, j, k} /\left(a c U_{t-1}+a d_{j, k} E P_{j, t-1}\right)\right] \\
N P_{i, j, k, t}= & 1 /\left(1+n a_{i, j, k} U_{t-i}^{n b_{i, j}}\right) \\
U N_{i, j, k, t}= & 1 /\left[1+u a_{i, j, k}\left(K_{t} / L_{t}\right) u b_{i, j, k}\right.
\end{aligned}
$$

\section{Determination of labor quality}

$$
\begin{aligned}
\bar{Q} L_{k, t}= & \left(\sum_{i, j} Q L_{i, j, k, t} H_{i, j, k, t} W_{i, j, k, t}\right) / L_{k, t} \\
Q L_{i, j, k, t}= & q a_{i, j, k, t} E K_{i, j, k, t}^{q b_{i, j, k}} J B_{i, j, k, t}\left(1-D B_{i, j, k, t}\right) \\
E K_{i, j, k, t}= & {\left[E K_{i, j-1, k, t-1}\left(1-A_{i, j-1, k, t-1}\right)+\left(A_{i, j-1, k, t-1}\right.\right.} \\
& \left.\quad-A_{i, j, k, t}\right)\left(E P_{j-1, t-1}+E P_{j-2, t-2}+\ldots\right. \\
& \left.\left.+E P_{5, t-j-5}\right)\right] /\left(1-A_{i, j, k, t}\right) \\
E P_{j, t}= & E X_{j, t} / \sum_{i, k} P_{i, j, k, t} A_{i, j, k, t} \\
E P_{j, t}=e r_{j} E P_{\text {primary grades,t }}[\bar{j}=\operatorname{secondary} \text { grades, higher grades }] & (21) \\
\sum_{j} E X_{j, t}= & E D_{t} \\
J B_{i, j, k, t}= & J B_{i, j-1, k, t-1}+j a_{j, k}\left(H_{i, j, k, t-1} W_{i, j-1, k, t-1} / P_{i, j-1, k, t-1}\right) \\
D B_{i, \bar{j}, k, t}= & 1 /\left[1+b a_{i, j, k}(1-b b)^{-t} U_{i-1}^{b c}\right]-b d_{i, j, k, t}
\end{aligned}
$$

Determination of capital stock quantity

$$
\begin{aligned}
& K_{t}=K_{t-1}(1-d)+I U_{t} \\
& I U_{t}=z_{1} I V_{t-1}+z_{2} I V_{t-2}+\ldots+z_{7} I V_{t-7} \\
& I V_{t}=S P_{t}+S G_{t}+d\left[\left(K_{t-1}+K_{t}\right) / 2\right] \\
& S P_{t}=s a P D I_{t}^{s b} P_{0-14, t}^{-s c} P_{65}^{-s d} \& \text { over, },+s f C F_{t} \\
& \left.P D I_{t}=Y_{t}+T R_{t}-d\left[K_{t-1}+K_{t}\right) / 2\right]-T_{t}-M C_{t} \\
& M C_{t}=\operatorname{ma}\left\{Y_{t}+T R_{t}-d\left[\left(K_{t-1}+K_{t}\right) / 2\right]-T_{t}\right\}^{m b} P C_{t}^{m c} \overline{M R_{t}^{m d}}
\end{aligned}
$$




$$
\begin{aligned}
\overline{M R}_{t}=\left(\sum_{i, j, k} P_{i, j, k, t} M R_{i, j, k, t}\right) / \sum_{i, j, k} P_{i, j, k, t} \\
C F_{t}=v a(1+v b)^{t} \\
S G_{t}=T_{t}+E A_{t}+M A_{t}-E D_{t}-P H_{t}-M I_{t}-T R_{t}-O C_{t} \\
T_{t}=Y_{t}\left(t a+t b U_{t}\right)+t c\left(X_{t}+M_{t}\right) \\
M_{t}=X_{t}+C F_{t}+E A_{t}+M A_{t} \\
X_{t}=x a(1+x b)^{t} \\
E A_{t}=w a(1+w b)^{t} \\
M A_{t}=\operatorname{ga}(1+g b)^{t} \\
E D_{t}=\operatorname{se}\left(T_{t}+f w E A_{t}+f g M A_{t}\right) P_{5-17, t}^{r e} \\
P H_{t}=\operatorname{sh}\left(T_{t}+f w E A_{t}+f g M A_{t}\right) P C_{t}^{r h}+x_{1} P C_{t} \\
\quad+x_{2} \sum_{i, j, k} P_{i, j, k, t} f e_{i, j, k, t} \\
M I_{t}=\operatorname{sm}+\operatorname{sn}\left(T_{t}+f w E A_{t}+f g M A_{t}\right)+(1-f g) M A_{t} \\
T R_{t}=\operatorname{st}\left(T_{t}+f w E A_{t}+f g M A_{t}\right) P C_{t}^{r t} \\
O C_{t}=\operatorname{so(}\left(T_{t}+f w E A_{t}+f g M A_{t}\right) P C_{t}^{r o}
\end{aligned}
$$

Determination of capital quality

$$
\begin{aligned}
Q K_{t}= & \left\{K_{t-1} Q K_{t-1}[1-d(q d)]+I U_{t} Q I U_{t}\right\} / K_{t} \\
Q I U_{t}= & {\left[z_{1} I V_{t-1} Q I V_{t-1}+z_{2} I V_{t-2} Q I V_{t-2}+\ldots\right.} \\
& \left.+z_{7} I V_{t-7} Q I V_{t-7}\right] / I U_{t} \\
Q I V_{t}= & \left(Q I D_{t} I D_{t}+Q I M_{t} I M_{t}\right) /\left(I D_{t}+I M_{t}\right) \\
Q I D_{t}= & {\left[d f+d g\left(I D_{t} / Y_{t}\right)\right](1+d h)^{t} } \\
Q I M_{t}= & m f(1+m g)^{t} \\
I D_{t}= & I V_{t}-I M_{t} \\
I M_{t}= & r m M_{t}
\end{aligned}
$$

Footnotes to appendix $A$ :

${ }^{a}$ Given the values of the parameters and the constraints on the value of $D$, this equation provides for the intended positive relationship between $F$ on the one hand and $D$ and $U$ on the other, but the same relationship could obviously have been established more simply.

'This functional form was used in order to constrain the dependent variable to be greater than zero and less than one.

'Each attendance rate was also constrained from exceeding 95 per cent of the rate applying to the given cohort in the previous year. That is,

$A_{i, j, k, t} \leqq 0.95 A_{i, j-1, k, t-1}$.

This constraint did not apply, however, at the youngest school-going age (five years). 


\begin{abstract}
${ }^{\mathrm{d}}$ The sum of the $z$ 's was constrained to equal one, which means that $\left(z_{1} \times 100\right)$ per cent of the investment undertaken in a given year was utilized (as a productive part of the capital stock) in the year following, $\left[\left(z_{1}+z_{2}\right) \times 100\right]$ was utilized in the year after that, $\left[\left(z_{1}+z_{2}+z_{3}\right) \times\right.$ $100]$ was utilized in the year after that, and so forth.
\end{abstract}

\title{
Appendix B
}

Glossary of terms

Listed below are the terms used in the model described above, excluding those structural constraints or parameters whose meanings are self-explanatory. All monetary terms are measured in millions of dollars, except where indicated.

A school attendance rate

aa parameter determining school attendance rate, increased for the policies of raising attendance rates

$B \quad$ number of live births (in thousands)

$b b \quad$ annual rate of improvement in medical technology affecting debility

$b d \quad$ change in debility rate due to malaria eradication policy

$b r_{i} \quad$ births of sex $i$ as a fraction of total births

ca weight of consumption needs

$C F \quad$ inflow of private foreign capital

$D$ death rate

d depreciation rate

$D B$ debility rate

$d c \quad$ annual rate of improvement in medical technology affecting mortality

de change in death rate due to malaria eradication policy

dh annual rate of technological progress embodied in domestically produced capital goods

$E A$ foreign economic aid

$E D \quad$ total education expenditures

$E K$ accumulated educational capital per nonstudent (in thousands of dollars)

$E P$ education expenditures per pupil (in thousands of dollars)

er, ratio between education expenditures per pupil in the $\bar{j}$ grades and education expenditures per pupil in the primary grades, changed for the policies involving a diversion of educational expenditures between grades

EX education expenditures for all pupils of a given age

$F \quad$ fertility rate

$f$ female

$f c$ annual rate of improvement in medical technology affecting fertility

fe change in fertility rate due to malaria eradication or birth control policies 
$f g$ fungibility of foreign military aid (fraction of such aid which in effect constitutes an addition to the government revenues available for general purposes)

$f w \quad$ fungibility of foreign economic aid

ga parameter determining foreign military aid, reduced for the disarmament policy

$g b \quad$ annual rate of increase in foreign military aid

$H$ mean annual hours of work among those working (in thousands)

$i \quad$ pertaining to each sex

$I D$ domestically produced capital goods

$I M \quad$ imported capital goods

$I U$ investment of prior years utilized for the first time

IV gross investment

$j \quad$ pertaining to each single-year age-group $(j=0,1,2, \ldots, 64,65$ and over)

$\bar{j} \quad$ pertaining to each multi-year age-group (e.g., 0-4 years, 5-9, 10-14, . .)

$J B$ index of accumulated on-the-job training

$K \quad$ capital stock

$k$ pertaining to each educational attainment group ( $k=$ secondary school graduate, primary school graduate, nongraduate)

$L \quad$ aggregate annual number of hours worked (in millions)

$M \quad$ imports

$m \quad$ male

$M A \quad$ foreign military aid

$M C$ private expenditures on medical care

$m g$ annual rate of technological progress embodied in imported capital goods

$M I \quad$ military expenditures

$M R \quad$ morbidity rate for sex-age-educational attainment group

$M R \quad$ aggregate morbidity rate

$m s \quad$ military service rate, reduced for the disarmament policy

$n \quad$ nongraduate (of primary school)

$N P \quad$ rate of nonparticipation for other reasons

$O C$ other current government expenditures

$P \quad$ population (in thousands)

$p \quad$ primary school graduate

$P C$ population of equivalent consumers (In thousands)

$P D I$ private disposable income

$P H \quad$ public health expenditures

qd index of quality of capital lost through depreciation

$Q I D$ index of quality of domestically produced capital goods

$Q I M$ index of quality of imported capital goods

$Q I U$ index of quality of utilized investment 


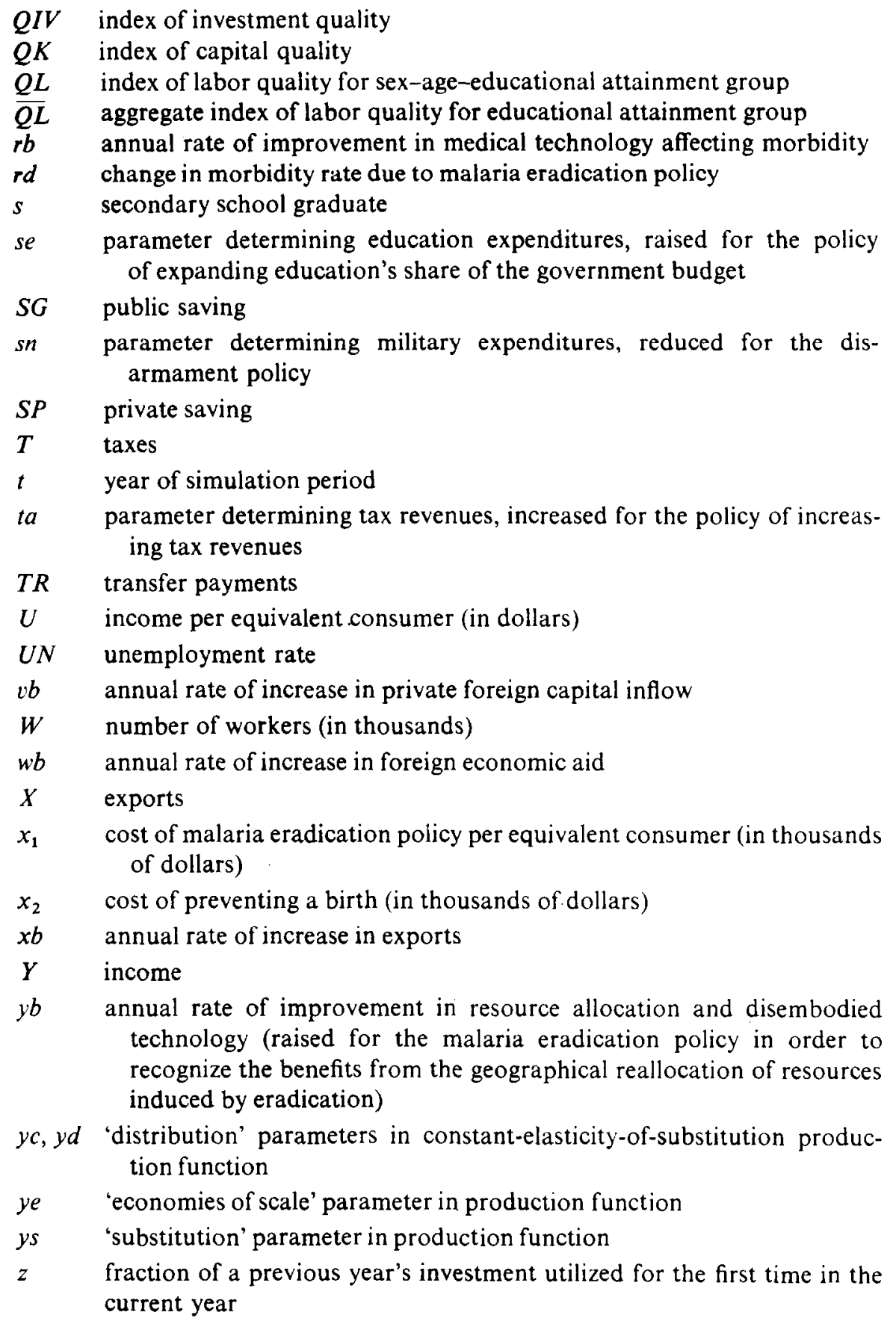




\section{Appendix $\mathbf{C}^{16}$}

\section{Values of exogenous terms}

Listed below are the values assumed for the parameters and exogenous variables in the basic simulation ('no policies') performed with the model described above. Footnotes indicate the statistical sources used as a basis for assigning some of the values.

\begin{tabular}{|c|c|c|c|c|c|}
\hline Term & Subscript & & Term & Subscript & \\
\hline \multirow[t]{7}{*}{$a a$} & $0-4$ & 0.0 & $a b^{\mathbf{a}}$ & $f, 18, s$ & 1.858 \\
\hline & $5-10$ & 1.0 & & $f, 19, s$ & 2.550 \\
\hline & $11-17, p$ & 1.0 & & $f, 20, s$ & 3.836 \\
\hline & $11 \&$ over, $n$ & 0.0 & & $f, 21, s$ & 7.050 \\
\hline & $18-24, s$ & 1.0 & & $f, 22, s$ & 22.050 \\
\hline & $18 \&$ over, $p$ & 0.0 & & $f, 23, s$ & 29.550 \\
\hline & $25 \&$ over, $s$ & 0.0 & & $f, 24, s$ & 63.836 \\
\hline \multirow[t]{33}{*}{$a b^{\mathbf{a}}$} & $m, 5$ & 0.073 & $a c$ & & 0.001 \\
\hline & $m, 6$ & 0.086 & $a d$ & $5-10$ & 27.273 \\
\hline & $m, 7$ & 0.100 & & $11-17, p$ & 6.818 \\
\hline & $m, 8$ & 0.113 & & $18-24, s$ & 6.818 \\
\hline & $m, 9$ & 0.127 & $b a^{0}$ & $m, 11-17, p$ & 11.719 \\
\hline & $m, 10$ & 0.142 & & $m, 11-17, n$ & 7.502 \\
\hline & $m, 11, p$ & 0.117 & & $m, 18-24, s$ & 12.839 \\
\hline & $m, 12, p$ & 0.141 & & $m, 18-24, p$ & 11.227 \\
\hline & $m, 13, p$ & 0.169 & & $m, 18-24, n$ & 7.184 \\
\hline & $m, 14, p$ & 0.200 & & $m, 25-34, s$ & 10.300 \\
\hline & $m, 15, p$ & 0.256 & & $m, 25-34, p$ & 9.211 \\
\hline & $m, 16, p$ & 0.325 & & $m, 25-34, n$ & 6.048 \\
\hline & $m, 17, p$ & 0.414 & & $m, 35-44, s$ & 8.701 \\
\hline & $m, 18, s$ & 1.281 & & $m, 35-44, p$ & 7.616 \\
\hline & $m, 19, s$ & 1.800 & & $m, 35-44, n$ & 5.554 \\
\hline & $m, 20, s$ & 2.764 & & $m, 45-54, s$ & 7.284 \\
\hline & $m, 21, s$ & 5.175 & & $m, 45-54, p$ & 6.484 \\
\hline & $m, 22, s$ & 10.800 & & $m, 45-54, n$ & 4.412 \\
\hline & $m, 23, s$ & 22.050 & & $m, 55-64, s$ & 5.161 \\
\hline & $m, 24, s$ & 44.550 & & $m, 55-64, p$ & 4.616 \\
\hline & $f, 5$ & 0.248 & & $m, 55-64, n$ & 3.137 \\
\hline & $f, 6$ & 0.264 & & $m, 65 \&$ over, $s$ & 2.892 \\
\hline & $f, 7$ & 0.281 & & $m, 65 \&$ over, $p$ & 2.571 \\
\hline & $f, 8$ & 0.300 & & $m, 65 \&$ over, $n$ & 1.636 \\
\hline & $f, 9$ & 0.319 & & $f, 11-17, p$ & 10.102 \\
\hline & $f, 10$ & 0.339 & & $f, 11-17, n$ & 6.484 \\
\hline & $f, 11, p$ & 0.256 & & $f, 18-24, s$ & 10.102 \\
\hline & $f, 12, p$ & 0.288 & & $f, 18-24, p$ & 9.050 \\
\hline & $f, 13, p$ & 0.325 & & $f, 18-24, n$ & 5.688 \\
\hline & $f, 14, p$ & 0.367 & & $f, 25-34, s$ & 8.701 \\
\hline & $f, 15, p$ & 0.441 & & $f, 25-34, p$ & 7.616 \\
\hline & $f, 16, p$ & 0.533 & & $f, 25-34, n$ & 5.366 \\
\hline & $f, 17, p$ & 0.652 & & $f, 35-44, s$ & 7.502 \\
\hline
\end{tabular}

${ }^{16}$ Footnotes $a-i$ at the end of appendix $C$. 


\begin{tabular}{|c|c|c|c|c|c|}
\hline Term & Subscript & & Term & Subscript & \\
\hline \multirow{16}{*}{$\begin{array}{l}b b \\
b c \\
b d \\
b r^{c}\end{array}$} & $f, 35-44, p$ & 6.660 & $d a^{e}$ & $f, 25-34, n$ & 47.2054 \\
\hline & $f, 35-44, n$ & 4.863 & & $f, 35-44, s$ & 51.5488 \\
\hline & $f, 45-54, s$ & 6.752 & & $f, 35-44, p$ & 47.2054 \\
\hline & $f, 45-54, p$ & 5.898 & & $f, 35-44, n$ & 43.5305 \\
\hline & $f, 45-54, n$ & 4.103 & & $f, 45-54, s$ & 35.0852 \\
\hline & $f, 55-64, s$ & 5.161 & & $f, 45-54, p$ & 31.1231 \\
\hline & $f, 55-64, p$ & 4.616 & & $f, 45-54, n$ & 27.9533 \\
\hline & $f, 55-64, n$ & 3.137 & & $f, 55-64, s$ & 27.9533 \\
\hline & $f, 65 \&$ over, $s$ & 2.892 & & $f, 55-64, p$ & 25.3607 \\
\hline & $f, 65 \&$ over, $p$ & 2.571 & & $f, 55-64, n$ & 23.1970 \\
\hline & $f, 65 \&$ over, $n$ & 1.745 & & $f, 65 \&$ over, $s$ & 5.9298 \\
\hline & & 0.01 & & $f, 65 \&$ over, $p$ & 5.5418 \\
\hline & & 0.11 & & $f, 65$ \& over, $n$ & 5.1689 \\
\hline & & 0.0 & $d b$ & $0-10$ & 1.0 \\
\hline & $m$ & 0.51 & & $11 \&$ over & 0.0 \\
\hline & $f$ & 0.49 & $d c$ & 0 & 0.0030 \\
\hline \multirow[t]{3}{*}{$c a^{\mathfrak{d}}$} & $0-10$ & 0.5 & & $1-64$ & 0.0025 \\
\hline & $m, 11 \&$ over & 1.0 & & 65 \& over, $s$ & 0.0025 \\
\hline & $f, 11 \&$ over & 0.9 & & 65 \& over, $p$ & 0.0025 \\
\hline$d$ & & 0.02 & & $65 \&$ over, $n$ & 0.0030 \\
\hline$d a^{\circ}$ & $m, 0$ & 2.1488 & $d d$ & 0 & 0.12 \\
\hline & $m, 1-4$ & 17.9977 & & $1-64$ & 0.10 \\
\hline & $m, 5-10$ & 113.7504 & & $65 \&$ over & 0.11 \\
\hline & $m, 11-17, p$ & 191.1155 & de & & 0.0 \\
\hline & $m, 11-17, n$ & 191.1155 & $d f$ & & 0.5273 \\
\hline & $m, 18-24, s$ & 114.0880 & $d g$ & & 5.0 \\
\hline & $m, 18-24, p$ & 114.0880 & $d h$ & & 0.015 \\
\hline & $m, 18-24, n$ & 94.9843 & $e r^{t}$ & $11-17$ & 2.0 \\
\hline & $m, 25-34, s$ & 94.9843 & & $18-24$ & 4.0 \\
\hline & $m, 25-34, p$ & 81.3338 & $f a^{\mathrm{e}}$ & $0-10$ & 0.0 \\
\hline & $m, 25-34, n$ & 71.0948 & & $11-17, p$ & 0.0354 \\
\hline & $m, 35-44, s$ & 56.7615 & & $11-17, n$ & 0.0507 \\
\hline & $m, 35-44, p$ & 51.5488 & & $18-24, s$ & 0.0857 \\
\hline & $m, 35-44, n$ & 47.2054 & & $18-24, p$ & 0.0915 \\
\hline & $m, 45-54, s$ & 40.3797 & & $18-24, n$ & 0.0975 \\
\hline & $m, 45-54, p$ & 35.0842 & & $25-34, s$ & 0.1480 \\
\hline & $m, 45-54, n$ & 31.1231 & & $25-34, p$ & 0.1547 \\
\hline & $m, 55-64, s$ & 23.1999 & & $25-34, n$ & 0.1623 \\
\hline & $m, 55-64, p$ & 20.4561 & & $35-44, s$ & 0.1152 \\
\hline & $m, 55-64, n$ & 18.3534 & & $35-44, p$ & 0.1233 \\
\hline & $m, 65 \&$ over, $s$ & 6.0858 & & $35-44, n$ & 0.1333 \\
\hline & $m, 65 \&$ over, $p$ & 5.6797 & $f b$ & $11-17$ & 0.0 \\
\hline & $m, 65 \&$ over, $n$ & 5.2913 & & $18-24, s$ & 0.2 \\
\hline & $f, 0$ & 2.3993 & & $18-24, p$ & 0.1 \\
\hline & $f, 1-4$ & 26.8263 & & $18-24, n$ & 0.0 \\
\hline & $f, 5-10$ & 113.7504 & & $25-34, s$ & 0.7 \\
\hline & $f, 11-17, p$ & 191.1155 & & $25-34, p$ & 0.6 \\
\hline & $f, 11-17, n$ & 143.4812 & & $25-34, n$ & 0.5 \\
\hline & $f, 18-24, s$ & 94.9843 & & $35-44, s$ & 1.0 \\
\hline & $f, 18-24, p$ & 94.9843 & & $35-44, p$ & 0.9 \\
\hline & $f, 18-24, n$ & 81.3338 & & $35-44, n$ & 0.8 \\
\hline & $f, 25-34, s$ & 56.7615 & $f c$ & & 0.001 \\
\hline & $f, 25-34, p$ & 51.5488 & $f d$ & $11-17$ & 0.10 \\
\hline
\end{tabular}




\begin{tabular}{|c|c|c|c|c|c|}
\hline Term & Subscript & & Term & Subscript & \\
\hline \multirow[t]{2}{*}{$f d$} & $\begin{array}{l}18-24 \\
25-34\end{array}$ & $\begin{array}{l}0.08 \\
0.06\end{array}$ & $j a$ & $\begin{array}{l}14 . p \\
14, n\end{array}$ & $\begin{array}{l}0.100 \\
0.050\end{array}$ \\
\hline & $35-44$ & 0.04 & & $15, p$ & 0.098 \\
\hline fe & & 0.0 & & $15, n$ & 0.049 \\
\hline$f_{g}$ & & 0.5 & & $16, p$ & 0.096 \\
\hline$f_{w}$ & & 0.8 & & $16, n$ & 0.048 \\
\hline$g a$ & & 12.50 & & $17, p$ & 0.094 \\
\hline$g b$ & & 0.04 & & $17, n$ & 0.047 \\
\hline \multirow[t]{41}{*}{ ha } & $0-10$ & 0.0 & & $18, p$ & 0.092 \\
\hline & $m, 11-17, p$ & 2.601 & & $18, n$ & 0.046 \\
\hline & $m, 11-17, n$ & 2.688 & & $19, s$ & 0.156 \\
\hline & $m, 18-24, s$ & 4.402 & & $19, p$ & 0.090 \\
\hline & $m, 18-24, p$ & 4.431 & & $19, n$ & 0.045 \\
\hline & $m, 18-24, n$ & 4.555 & & $20, s$ & 0.153 \\
\hline & $m, 25-34, s$ & 4.797 & & $20, p$ & 0.088 \\
\hline & $m, 25-34, p$ & 4.798 & & $20, n$ & 0.044 \\
\hline & $m, 25-34, n$ & 4.972 & & $21, s$ & 0.149 \\
\hline & $m, 35-44, s$ & 5.020 & & $21, p$ & 0.086 \\
\hline & $m, 35-44, p$ & 5.064 & & $21, n$ & 0.043 \\
\hline & $m, 35-44, n$ & 5.192 & & $22, s$ & 0.146 \\
\hline & $m, 45-54, s$ & 4.724 & & $22, p$ & 0.084 \\
\hline & $m, 45-54, p$ & 4.765 & & $22, n$ & 0.042 \\
\hline & $m, 45-54, n$ & 4.937 & & $23, s$ & 0.143 \\
\hline & $m, 55-64, s$ & 4.310 & & $23, p$ & 0.082 \\
\hline & $m, 55-64, p$ & 4.358 & & $23, n$ & 0.041 \\
\hline & $m, 55-64, n$ & 4.564 & & $24, s$ & 0.139 \\
\hline & $m, 65 \&$ over, $s$ & 3.646 & & $24, p$ & 0.080 \\
\hline & $m, 65 \&$ over, $p$ & 3.740 & & $24, n$ & 0.040 \\
\hline & $m, 65 \&$ over, $n$ & 4.228 & & $25, s$ & 0.136 \\
\hline & $f, 11-17, p$ & 1.921 & & $25, p$ & 0.078 \\
\hline & $f, 11-17, n$ & 1.978 & & $25, n$ & 0.039 \\
\hline & $f, 18-24, s$ & 3.318 & & $26, s$ & 0.132 \\
\hline & $f, 18-24, p$ & 3.340 & & $26, p$ & 0.076 \\
\hline & $f, 18-24, n$ & 3.454 & & $26, n$ & 0.038 \\
\hline & $f, 25-34, s$ & 3.612 & & $27, s$ & 0.129 \\
\hline & $f, 25-34, p$ & 3.643 & & $27, p$ & 0.074 \\
\hline & $f, 25-34, n$ & 3.764 & & $27, n$ & 0.037 \\
\hline & $f, 35-44, s$ & 3.824 & & $28, s$ & 0.125 \\
\hline & $f, 35-44, p$ & 3.858 & & $28, p$ & 0.072 \\
\hline & $f, 35-44, n$ & 3.965 & & $28, n$ & 0.036 \\
\hline & $f, 45-54, s$ & 3.584 & & $29, s$ & 0.122 \\
\hline & $f, 45-54, p$ & 3.623 & & $29, p$ & 0.070 \\
\hline & $f, 45-54, n$ & 3.755 & & $29, n$ & 0.035 \\
\hline & $f, 55-64, s$ & 3.209 & & $30, s$ & 0.118 \\
\hline & $f, 55-64, p$ & 3.245 & & $30, p$ & 0.068 \\
\hline & $f, 55-64, n$ & 3.398 & & $30, n$ & 0.034 \\
\hline & $f, 65$ \& over, $s$ & 2.661 & & $31, s$ & 0.115 \\
\hline & $f, 65 \&$ over, $p$ & 2.661 & & $31, p$ & 0.066 \\
\hline & $f, 65 \&$ over, $n$ & 2.998 & & $31, n$ & 0.033 \\
\hline$h b$ & & 0.10 & & $32, s$ & 0.111 \\
\hline \multirow{4}{*}{ ja } & $12, p$ & 0.104 & & $32, p$ & 0.064 \\
\hline & $12, n$ & 0.052 & & $32, n$ & 0.032 \\
\hline & $13, p$ & 0.102 & & $33, s$ & 0.108 \\
\hline & $13, n$ & 0.051 & & $33, p$ & 0.062 \\
\hline
\end{tabular}




\begin{tabular}{|c|c|c|c|c|c|}
\hline Term & Subscript & & Term & Subscript & \\
\hline \multirow[t]{52}{*}{ ja } & $33, n$ & 0.031 & $j a$ & $51, s$ & 0.045 \\
\hline & $34, s$ & 0.104 & & $51, p$ & 0.026 \\
\hline & $34, p$ & 0.060 & & $51, n$ & 0.013 \\
\hline & $34, n$ & 0.030 & & $52, s$ & 0.042 \\
\hline & $35, s$ & 0.101 & & $52, p$ & 0.024 \\
\hline & $35, p$ & 0.058 & & $52, n$ & 0.012 \\
\hline & $35, n$ & 0.029 & & $53, s$ & 0.038 \\
\hline & $36, s$ & 0.097 & & $53, p$ & 0.022 \\
\hline & $36, p$ & 0.056 & & $53, n$ & 0.011 \\
\hline & $36, n$ & 0.028 & & $54, s$ & 0.035 \\
\hline & $37, s$ & 0.094 & & $54, p$ & 0.020 \\
\hline & $37, p$ & 0.054 & & $54, n$ & 0.010 \\
\hline & $37, n$ & 0.027 & & $55, s$ & 0.031 \\
\hline & $38, s$ & 0.090 & & $55, p$ & 0.018 \\
\hline & $38, p$ & 0.052 & & $55, n$ & 0.009 \\
\hline & $38, n$ & 0.026 & & $56, s$ & 0.028 \\
\hline & $39, s$ & 0.087 & & $56, p$ & 0.016 \\
\hline & $39, p$ & 0.050 & & $56, n$ & 0.008 \\
\hline & $39, n$ & 0.025 & & $57, s$ & 0.024 \\
\hline & $40, s$ & 0.083 & & $57, p$ & 0.014 \\
\hline & $40, p$ & 0.048 & & $57, n$ & 0.007 \\
\hline & $40, n$ & 0.024 & & $58, s$ & 0.020 \\
\hline & $41, s$ & 0.080 & & $58, p$ & 0.012 \\
\hline & $41, p$ & 0.046 & & $58, n$ & 0.006 \\
\hline & $41, n$ & 0.023 & & $59, s$ & 0.017 \\
\hline & $42, s$ & 0.076 & & $59, p$ & 0.010 \\
\hline & $42, p$ & 0.044 & & $59, n$ & 0.005 \\
\hline & $42, n$ & 0.022 & & $60, s$ & 0.014 \\
\hline & $43, s$ & 0.073 & & $60, p$ & 0.008 \\
\hline & $43, p$ & 0.042 & & $60, n$ & 0.004 \\
\hline & $43,: 1$ & 0.021 & & $61, s$ & 0.010 \\
\hline & $44, s$ & 0.070 & & $61, p$ & 0.006 \\
\hline & $44, p$ & 0.040 & & $61, n$ & 0.003 \\
\hline & $44, n$ & 0.020 & & $62, s$ & 0.007 \\
\hline & $45, s$ & 0.066 & & $62, p$ & 0.004 \\
\hline & $45, p$ & 0.038 & & $62, n$ & 0.002 \\
\hline & $45, n$ & 0.019 & & $63, s$ & 0.003 \\
\hline & $46, s$ & 0.063 & & $63, p$ & 0.002 \\
\hline & $46, p$ & 0.036 & & $63, n$ & 0.001 \\
\hline & $46, n$ & 0.018 & & $64 \&$ over & 0.0 \\
\hline & $47, s$ & 0.059 & $m a^{r}$ & & 0.375 \\
\hline & $47, p$ & 0.034 & $m b$ & & 1.0 \\
\hline & $47, n$ & 0.017 & $m c$ & & 0.0 \\
\hline & $48, s$ & 0.056 & $m d$ & & 1.0 \\
\hline & $48, p$ & 0.032 & $m f$ & & 1.5207 \\
\hline & $48, n$ & 0.016 & $m g$ & & 0.015 \\
\hline & $49 . s$ & 0.052 & $m s$ & $0-10$ & 0.0 \\
\hline & $49, p$ & 0.030 & & $m, 11-17$ & 0.05 \\
\hline & $49, n$ & 0.015 & & $m, 18-24, s$ & 0.25 \\
\hline & $50, s$ & 0.049 & & $m, 18-24, p$ & 0.30 \\
\hline & $50, p$ & 0.028 & & $m, 18-24, n$ & 0.35 \\
\hline & $50, n$ & 0.014 & & $m, 25-34, s$ & 0.05 \\
\hline
\end{tabular}




\begin{tabular}{|c|c|c|c|c|c|}
\hline Term & Subscript & & Term & Subscript & \\
\hline \multirow[t]{10}{*}{$m i s$} & $m, 25-34, p$ & 0.10 & re & & 0.25 \\
\hline & $m, 25-34, n$ & 0.15 & $r h$ & & 0.25 \\
\hline & $f, 11-17$ & 0.0 & $r m^{\circ}$ & & 0.30 \\
\hline & $f, 18-24, s$ & 0.05 & ro & & 0.25 \\
\hline & $f, 18-24, p$ & 0.05 & $r t$ & & 0.25 \\
\hline & $f, 18-24, n$ & 0.02 & $s a^{\mathrm{h}}$ & & 16.2822 \\
\hline & $f, 25-34, s$ & 0.02 & $s b^{n}$ & & 1.12 \\
\hline & $f, 25-34, p$ & 0.02 & $s c^{\mathrm{h}}$ & & 0.655 \\
\hline & $f, 25-34, n$ & 0.01 & $s d^{\mathrm{h}}$ & & 0.225 \\
\hline & $35 \&$ over & 0.0 & $s e^{\mathfrak{c}}$ & & 0.0123 \\
\hline \multirow[t]{24}{*}{$n a^{\prime}$} & $0-10$ & 0.0 & $s f$ & & 0.9 \\
\hline & $m, 11-17, p$ & 2.333 & $s h^{\mathrm{c}}$ & & 0.0061 \\
\hline & $m, 11-17, n$ & 4.000 & $s m$ & & 20.0 \\
\hline & $m, 18-24, s$ & 1.857 & $s n$ & & 0.15 \\
\hline & $m, 18-24, p$ & 5.667 & so & & 0.0322 \\
\hline & $m, 18-24, n$ & 19.000 & $s t^{\mathrm{e}}$ & & 0.0308 \\
\hline & $m, 25-34, s$ & 19.000 & $t$ & & $1-31$ \\
\hline & $m, 25-34, p$ & 49.000 & $i a^{\prime}$ & & 0.102 \\
\hline & $m, 25-34, n$ & 49.000 & $t^{i}$ & & 0.0001 \\
\hline & $m, 35-44$ & 49.000 & $t c^{\prime}$ & & 0.07 \\
\hline & $m, 45-54$ & 19.000 & $u a^{\prime}$ & $m, 11-17, p$ & 9.989 \\
\hline & $m, 55-64$ & 5.667 & & $m, 11-17, n$ & 4.765 \\
\hline & $f, 11-17, p$ & 68892.0 & & $m, 18-24, s$ & 3.348 \\
\hline & $f, 11-17, n$ & 351.7 & & $m, 18-24, p$ & 4.529 \\
\hline & $f, 18-44, s$ & 68892.0 & & $m, 18-24, n$ & 5.020 \\
\hline & f $18-44, p$ & 1694.5 & & $m, 25-34$ & 9.989 \\
\hline & $f, 18-44, n$ & 351.7 & & $m, 35-44, s$ & 15.523 \\
\hline & $f, 45-54, s$ & 1694.5 & & $m, 35-44, p$ & 12.132 \\
\hline & $f, 45-54, p$ & 351.7 & & $m, 35-44, n$ & 9.989 \\
\hline & $f, 45-54, n$ & 151.8 & & $m, 45-54, s$ & 20.906 \\
\hline & $55-64, s$ & 68892.0 & & $m, 45-54, p$ & 15.525 \\
\hline & $f, 55-64, p$ & 1694.5 & & $m, 45-54, n$ & 12.132 \\
\hline & $f, 55-64, n$ & 351.7 & & $m, 55-64, s$ & 25.204 \\
\hline & $65 \&$ over & 0.0 & & $m, 55-64, p$ & 20.906 \\
\hline \multirow[t]{13}{*}{$n b$} & $m$ & 0.0 & & $m, 55-64, n$ & 17.582 \\
\hline & $f, 11-17, p$ & 2.50 & & $f, 11-17, p$ & 20.906 \\
\hline & $f, 11-17, n$ & 1.25 & & $f, 11-17, n$ & 12.132 \\
\hline & $f, 18-44, s$ & 2.50 & & $f, 18-24, s$ & 3.943 \\
\hline & $f, 18-44, p$ & 1.65 & & $f, 18-24, p$ & 5.632 \\
\hline & $f, 18-44, n$ & 1.25 & & $f, 18-24, n$ & 9.989 \\
\hline & $f, 45-54, s$ & 1.65 & & $f, 25-34$ & 15.523 \\
\hline & $f, 45-54, p$ & 1.25 & & $f, 35-44, s$ & 32.367 \\
\hline & $f, 45-54, n$ & 1.00 & & $f, 35-44, p$ & 20.906 \\
\hline & $f, 55-64, s$ & 2.50 & & $f, 35-44, n$ & 15.523 \\
\hline & $f, 55-64, p$ & 1.65 & & $f, 45-64, s$ & 62.510 \\
\hline & f. $55-64, n$ & 1.25 & & $f, 45-64, p$ & 43.476 \\
\hline & $f, 65$ \& over & 0.0 & & $f, 45-64, n$ & 32.367 \\
\hline qa & & 1.9248 & & 65 \& over & 0.0 \\
\hline$q b$ & & 0.2337 & $u b$ & $m, 11-17, p$ & 0.456 \\
\hline$q p$ & & 0.8 & & $m, 11-17, n$ & 0.522 \\
\hline$r a^{8}$ & & same as $b a$ & & $m, 18-24, s$ & 0.576 \\
\hline$r b$ & & 0.01 & & $m, 18-24, p$ & 0.530 \\
\hline$r c$ & & 0.11 & & $m, 18-24, n$ & 0.516 \\
\hline$r d$ & & 0.0 & & $m, 25-34$ & 0.456 \\
\hline
\end{tabular}




\begin{tabular}{|c|c|c|c|c|c|}
\hline Term & Subscript & & Term & Subscript & \\
\hline$u b$ & $\begin{array}{l}m, 35-44, s \\
m, 35-44, p \\
m, 35-44, n \\
m, 45-54, s \\
m, 45-54, p \\
m, 45-54, n \\
m, 55-64, s \\
m, 55-64, p \\
m, 55-64, n \\
f, 11-17, p \\
f, 11-17, n \\
f, 18-24, s \\
f, 18-24, p \\
f, 18-24, n \\
f, 25-34 \\
f, 35-44, s \\
f, 35-44, p \\
f, 35-44, n \\
f, 45-54, s \\
f, 45-54, p \\
f, 45-54, n \\
f, 55-64, s \\
f, 55-64, p \\
f, 55-64, n\end{array}$ & $\begin{array}{l}0.436 \\
0.446 \\
0.456 \\
0.426 \\
0.436 \\
0.446 \\
0.422 \\
0.426 \\
0.432 \\
0.426 \\
0.446 \\
0.544 \\
0.502 \\
0.456 \\
0.436 \\
0.416 \\
0.426 \\
0.436 \\
0.408 \\
0.412 \\
0.416 \\
0.408 \\
0.412 \\
0.416\end{array}$ & $\begin{array}{l}u b \\
v a \\
v b \\
w a \\
w b \\
x \\
x a \\
x b \\
y a \\
y b \\
y c^{d} \\
y d^{\prime} \\
\\
y e \\
y s \\
z\end{array}$ & $\begin{array}{l}1 \\
2 \\
3 \\
4 \\
5 \\
6 \\
7\end{array}$ & $\begin{array}{c}0.0 \\
25.0 \\
0.04 \\
25.0 \\
0.04 \\
0.0 \\
0.0 \\
223.0 \\
0.02 \\
0.1379 \\
0.005 \\
0.4671 \\
0.0263 \\
0.1445 \\
0.3621 \\
1.11 \\
0.1111 \\
0.27 \\
0.21 \\
0.16 \\
0.12 \\
0.09 \\
0.08 \\
0.07\end{array}$ \\
\hline
\end{tabular}

Footnotes to appendix $C$ :

${ }^{2}$ Director of Education, Government of Ceylon (various years).

${ }^{b}$ Barlow (1969).

'Department of Census and Statistics (various years).

${ }^{\circ}$ Coale and Hoover (1958).

'Newman (1965).

'Central Bank of Ceylon (1963).

Cullumbine (1952, 1953).

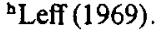

'Lotz and Morss (1970).

\section{References}

Arrow, K.J., H.B. Cherrery, B. Minhas and R.M. Solow, Capital-labor substitution and econonic efficiency, Review of Economics and Statistics 43, 225-250.

Barlow, R., 1969, The economic effects of malaria eradication (Bureau of Public Health Economics, University of Michigan, Ann Arbor, Mich.).

Bowles, S., 1967, The efficient allocation of resources in education, Quarterly Journal of Economics 81, 189-219.

Central Bank of Ceylon, 1963, Survey of consumer finances.

Chakravarty, S., 1969, Capital and development planning (M.I.T. Press, Cambridge, Mass.) 71-79.

Chenery, H.B. and P. Eckstein, 1970, Development alternatives for Latin America, Journal of Political Economy 78, 966-1006.

Coale, A.J. and E.M. Hoover, 1958, Population growth and economic development in lowincome countries (Princeton University Press, Princeton, N.J.).

Cullumbine, H., 1952, A survey of disabling illiness in Ceylon, Bulletin of the World Health Organisation 7, 405-429. 
Cullumbine, H., 1953, The health of a tropical people, The Lancet 264, 1090-1092, 1144-1147, 1193-1196, 1245-1246.

Davies, G.W., 1972, An economic-demographic simulation model designed to tzst the effects of changes in the rate and skill composition of net immigration on the Canadian economy from 1952 to 1968, unpublished doctoral dissertation (University of Michigan, Ann Arbor, Mich.).

Denton, F.T. and B.G. Spencer, 1971, A simulation analysis of the effects of population change on a neoclassical economy, Working paper no. 71-01 (Department of Economics, McMaster University, Hamilton, Ont.).

Department of Census and Statistics, various years, Statistical abstract of Ceyton.

Director of Education, Government of Ceylon, various years, Administration report.

Enke, S. and R.G. Zind, 1969, Effect of fewer births on average income, Journal of Biosocial Science, $41-55$.

Enke, S. et al., n.d., Population growth and economic development, TEMPO, 5 vols. (Santa Barbara, Calif.).

Fromm, G. and P. Taubman, 1968, Policy simulations with an econometric model (The Brookings Institution, Washington, D.C.).

Holland, E.P. and R.W. Gillespie, 1963, Experiments on a simulated underdeveloped economy: Development plans and balance-of-payments policies (M.I.T. Press, Cambridge, Mass.).

Jennings, I., 1951, The economy of Ceylon, 2nd ed. (Oxford University Press, Oxford).

Leff, N., 1969, Dependency rates and savings rates, American Economic Review 59, 886-896.

Lotz, J. and E.R. Morss, 1970, A theory of tax level determinants for developing countries, Economic Development and Cultural Change 18, 328-341.

Newman, P., 1965, Malaria eradication and population growth (Bureau of Public Health Economics, University of Michigan, Ann Arbor, Mich.). 